Recepción: 13 / 02 / 2018

Aceptación: 09 / 04 / 2018

Publicación: 05 / 06 / 2018

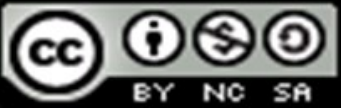

Ciencias de la comunicación

Artículo de investigación

\title{
La presencia de la semiótica en la sociedad
}

\section{The presence of semiotics in society}

\section{A presença da semiótica na sociedade}

\author{
Urcinio T. Toala-Castro ${ }^{\mathrm{I}}$ \\ tomastoala@yahoo.es \\ Vicente I. Reyna-Moreira II \\ vireymo@hotmail.es \\ Sonnia P. Yépez-Cedeño ${ }^{\mathrm{III}}$ \\ sonniayepez@yahoo.es
}

Correspondencia: tomastoala@yahoo.es

\footnotetext{
I Magister en Gerencia Educativa, Diploma Superior en Educación Universitaria por Competencias, Especialista en Diseño Curricular por Competencias, Licenciado en Ciencias de la Educación Especialidad Música, Profesor de Segunda Enseñanza Especialidad Música, Universidad Laica Eloy Alfaro de Manabí, Manta, Ecuador.

II Magister en Gerencia Educativa, Profesora de Segunda Enseñanza, Licenciado en Ciencias de la Educación Espec. Psicología y Orientación Vocacional, Universidad Laica Eloy Alfaro de Manabí, Manta, Ecuador.

III Magister en Ciencias de la Educación, Diploma Superior en Educación Universitaria por Competencias, Licenciada en Ciencias de la Educación Espec. Historia y Geografía, Profesora de Segunda Enseñanza Especialización Ciencias Sociales.
} 


\title{
Resumen
}

El presente trabajo tuvo como propósito caracterizar la presencia de la semiótica en la sociedad, entendiéndola como fundamental para una adecuada comunicación entre las personas. La presente investigación está delimitada dentro del área de la lingüística, específicamente en referencia a la semiótica. La metodología fue de tipo descriptiva y no-experimental con un enfoque documental y bajo una postura epistemológica basada en el idealismo-deductivo. La recolección de la información estuvo vinculada a partir de la consulta de libros y documentos de internet. Del análisis de contenido se pudo concluir que la semiótica es la concordancia que existe entre un objeto y su interpretación, lo que vemos y lo que nos dice es decir nos transmite un mensaje, el mismo que es comprendido por todos los seres humanos que hablamos una misma lengua.

Palabras clave: semiótica; signos; sociedad; comunicación.

\begin{abstract}
The purpose of this work was to characterize the presence of semiotics in society, understanding it as fundamental for an adequate communication between people. The present investigation is delimited within the area of linguistics, specifically in reference to semiotics. The methodology was descriptive and non-experimental with a documentary approach and an epistemological position based on deductive idealism. The collection of information was linked from the consultation of books and internet documents. Content analysis could conclude that semiotics is the agreement that exists between an object and its interpretation, what we see and what it tells us is that it transmits a message, the same that is understood by all the human beings that we speak same language.
\end{abstract}

Keywords: semiotics; signs; society; communication.

\section{Resumo}

O objetivo deste trabalho foi caracterizar a presença da semiótica na sociedade, entendendo-a como fundamental para uma comunicação adequada entre as pessoas. A presente investigação está delimitada dentro da área da linguística, especificamente em referência à semiótica. A 
metodologia foi descritiva e não experimental, com uma abordagem documental e uma posição epistemológica baseada no idealismo dedutivo. A coleta de informações foi vinculada a partir da consulta de livros e documentos da internet. A análise de conteúdo poderia concluir que a semiótica é o acordo que existe entre um objeto e sua interpretação, o que vemos e o que ele nos diz é que ele transmite uma mensagem, a mesma que é entendida por todos os seres humanos que falamos mesma língua.

Palavras chave: semiótica; sinais; sociedade; comunicação.

\section{Introducción}

El estudio de la semiótica en la sociedad surge a raíz de las críticas de diversos autores a la semiótica trabajada en general desde todas las disciplinas a lo largo del siglo XX: una semiótica excesivamente centrada en el estudio del signo que ignora la vida de dichos signos en las prácticas sociales. Ha prevalecido una especie de ceguera disciplinaria en la que todos los sociocientíficos en materia de comunicación se interesan por el "quién", "dice qué", " en qué canal", " a quién" y "con qué efectos" pero no se preguntan lo más importante que el "cómo" la comunicación y sus efectos se transmiten en el discurso.

En este sentido, se conoce como semiótica a la palabra cuyo interés son los signos. Esta teoría analiza la presencia de los signos y su utilización en la cotidianidad de la vida. La Real Academia Española (RAE), nos dice que la semiótica es la ciencia que estudia los diferentes sistemas de signos que permiten la comunicación entre los seres humanos, su elaboración, su funcionamiento y aceptación, nos indica que Semiótica es sinónimo de Semiología (Teoría general de los signos). Aunque varios autores establecen algunas diferencias por lo que le dan diferentes definiciones, sin embargo todos coinciden en que la semiótica no se trata de un acto de lectura; sino de una actitud de indagación de lo que existe de base en toda significación: sus raíces y los elementos que la sustentan. (Pérez Julián y Gardey Ana, 2008).

La semiótica también es conocida como Teoría de Signos y plantea el funcionamiento del pensamiento del ser humano estudiando todo el proceso cognitivo. En otras palabras, la semiótica establece y trata de dar respuesta a la interrogante de cómo el ser humano conoce el mundo que lo rodea, cómo lo interpreta, cómo genera conocimiento y cómo lo transmite. Por lo tanto, la semiótica buscará encontrar los mecanismos que llevan al hombre o a la mujer a establecer una 
relación de significado con algo, que puede ser un objeto, un gráfico, una imagen, un sonido o una combinación de éstos, de tal forma que al volver a entrar en contacto con éste, su mente recordará el significado con el que se ligó en un principio. (Eco, 2005).

Para Ferdinand de Saussure (2007) la definición o significado comienza a partir de la existencia del signo. El signo es una unidad dual de significado y significante, que ha determinado muchas de las definiciones posteriores de la semiótica. La relación entre significante y significado se establece sobre la lengua; es decir, un sistema de signos y reglas para utilizar dichos signos cuya característica principal recae en su fonetismo y su capacidad de ser ligada a signos gráficos que finalmente representan la sonoridad de los signos de la lengua.

Por lo que podemos decir que la semiótica se encuentra en todas las ciencias que se dedican al estudio de los signos en todos campos del conocimiento porque la ven como una ciencia encauzada a estudiar cómo se desempeña el pensamiento para manifestar los comportamientos e interpretación del medio y su transmisión hacia los demás. Esto involucra a la misma intentando explicar la forma en la que los humanos utilizan los signos para comprender su hábitat y para comunicarse con otras personas. El hombre es un ser sociable por naturaleza, desde que este apareció en la tierra ha formado clanes, hordas, etc., sea para defenderse de los animales o del clima o para compartir actividades cotidianas, en la actualidad le llamamos familia, la familia no solo es la consanguínea con la que habitas en una casa, sino la que comparte el trabajo, los estudios, las fiestas, los vecinos, entre otros. Ante este planteamiento, se propone en este artículo caracterizar la presencia de la semiótica en la sociedad.

\section{Desarrollo}

Desde la antigüedad el ser humano ha buscado la forma de entenderse y lo descubrimos por los pictogramas realizados en las cuevas rupestres en donde personalizaban su hábitat, los egipcios en sus jeroglíficos, las culturas precolombinas que por medio del estudio de las estrellas entendieron al mundo que les rodeaba y lo representaron en sus actividades diarias como la numeración Maya, ya que fueron los primeros en simbolizar el cero como un número sin valor, también la numeración azteca basada en el maíz como su principal fuente de alimento, de trabajo y de vida. El calendario inca muy parecido al actual y el quipu (conjunto de cuerdas con nudos y cada nudo representaba una cantidad según donde iba colocado el más alto representaba los 
miles, seguían las centenas, las decenas y por último las unidades) utilizado para contabilizar sus cultivos, intercambios o realizar el censo poblacional. La forma que emplea el hombre los diferentes signos a la hora de comunicarse es muy amplia y variada como ya conocemos esta puede ser oral, escrita, mímica y/o simbólica, en la actualidad con el avance de la tecnología con el internet tenemos una nueva manera de comunicarnos como es la digital. Los pictogramas, jeroglíficos, gráficos, dibujos, idiomas, braille, gestos, etc., son las representaciones a las que les hemos dado un significado para entendernos unos a otros por medio de las relaciones que se establecen entre los diversos significantes.

En el sistema comunicativo actual, el signo lingüístico es estudiado como la relación principal de la Lengua, ya que las grafías son la forma como representamos las letras a las que les damos un significado para entendernos de manera clara y precisa. Matemáticamente las figuras geométricas, los números y los símbolos representan los ejercicios que son utilizados en el diario vivir, estos están formado por un significante (como lo pronunciamos) y un significado (la idea que crea el signo en nuestra mente). En el área de Ciencias Naturales las fórmulas químicas son un vocabulario tangible para los científicos y estudiosos de la materia. Como podemos observar todas las ciencias tienen sus símbolos y simbologías para expresar sus descubrimientos. Para Charles Pierce (1839-1914), "el signo es una entidad compuesta por el significante (el soporte material), el significado (la imagen mental) y el referente (el objeto, ya sea imaginario o real, al que alude el signo)". Por lo tanto estudiamos la relación que existe entre un objeto y su nombre en otras palabras el signo nos transmite un mensaje.

En otras palabras, indica Eco (2005), la lengua tiene como principal objetivo comunicar información o ideas, y para ello, se basa en sonidos pronunciados y reconocidos por ciertos grupos sociales. Dichos sonidos pueden escribirse, es decir, pueden tener una dimensión gráfica, pero finalmente nos darán a conocer un grupo de sonidos que a su vez remiten a un significado específico. Por su parte Buyssens (2012), considera a la semiótica una actividad, es decir, una doctrina de la naturaleza esencial y de las variedades fundamentales de cualquier clase posible de semiosis.

Cabe destacar, el rol de la semiótica que desde la publicidad nos envuelve, nos enamora, nos convence, nos transforma y transporta a su antojo porque nos motiva a consumir lo que ofrece, 
nos mueve en masas, quien no ha observado las propagandas en las redes sociales, en la televisión, en la radio, en el periódico, en los anuncios en las calles; visual y auditivamente han sido hechas para llamar la atención e invitarnos a mirarla no una vez sino muchas veces hasta que nos persuade de comprarla; por otro lado también la semiótica se utiliza como un elemento de prevención como: los semáforos, las señales de tránsito que se encuentran en los costados de las carreteras, las señaléticas de evacuación en las instituciones públicas, otro de sus objetivos es su variedad en la interpretación (significado), porque puede decirnos varias cosas a la vez según su contexto un muestra práctica serían los sinónimos como: pie (parte del cuerpo, pastel, pedestal, fundamento, etc.). La sociedad nos enseña a interpretar su simbología, ejemplo la bandera de su patria, una bandera a media asta, una bengala sobre el océano, el doblar de las campanas de una iglesia. Asimismo, son notables los signos que intervienen en todo este andar del mundo de la semiótica.

\section{Tipos de signos}

Entendiendo que la semiótica tiene como elementos básicos al significado, que es la abstracción que define y delimita a algo en la realidad, y el signo, que será aquel elemento que al entrar en contacto con un intérprete transmitirá la abstracción de la realidad.

El símbolo. Es un tipo de signo que además de contener un plano de la realidad específico, también tiene direccionalidad y tonalidad definida por la cultura y la historia de la comunidad en particular en la que se presenta, pues evoca valores y sentimientos, representando ideas abstractas de una manera metafórica o alegórica. El significado de los símbolos se le atribuye principalmente a la comunidad y la temporalidad en la que viven. Es completamente convencional, de tal forma que difícilmente encontraremos símbolos en la comunicación entre animales, plantas o robots, pues tiene un fuerte lazo con la intencionalidad y la voluntad por dotar a un signo con características que van más allá de lo que representaría por sí mismo.

El ícono. De acuerdo con Chandler (2007), el ícono es un tipo de signo que imita o se parece en gran medida al significado. Es decir, que los trazos, los sonidos, las texturas, los olores, los gestos, etcétera, son parecidos al modelo original. El ícono tiene que ser similar o poseer alguna de las características del modelo original, como ocurre con los retratos, las caricaturas, los modelos a escala, las onomatopeyas, las metáforas, las imitaciones gestuales de los mimos, entre 
muchos otros rasgos reproducibles. Por su propia naturaleza, el ícono envuelve un cierto grado de convencionalidad, pues establece rasgos que una sociedad ha dado por hecho que representa al modelo de la realidad.

El signo. Ferdinand Saussure (2007), plantea la necesidad de identificar las premisas que puedan caracterizar el concepto de signo lingüístico; es decir, identificar su perfil dual, en una unidad. De acuerdo con el padre de la semiótica, el signo lingüístico une un concepto y una imagen acústica y los dos elementos están unidos en nuestro cerebro por un vínculo de asociación.

La señal. Es un tipo de signo que tiene el propósito determinado de informar o dar direcciones específicas a un público general. Son colocados y diseñados de forma que 99 por ciento de las personas tengan contacto con ellos. Pueden ser visibles, sonoros o táctiles. Están hechas con la intención de comunicar. Por lo tanto, aunque la presencia de humo puede ser puesto por algunas personas como señal de un incendio, realmente es un signo de un incendio (signo natural, porque son producidos o generados por la naturaleza), pues no hubo voluntad de crear el humo para comunicar la presencia de un incendio; en cambio si el humo está fabricado por seres humanos específicamente para comunicar que hay un incendio, sólo así se le tomará por señal. Como el objetivo principal de una señal es dar el aviso a un público general, sin tomar en cuenta perfiles como la alfabetización, el color de piel, las creencias religiosas, la cultura de la que provengan, etcétera, la señal debe ser obvia y fácilmente interpretable, de tal forma que su relación con la realidad debe ser lo más fidedigna y sencilla posible.

\section{Fases de la Semiótica Social}

Fase de pre-exposición: intérprete inmediato, esta se inicia cuando se empiezan a recibir las primeras informaciones en los medios acerca de algo pero aún no sabemos exactamente el qué, el intérprete recibe significados potenciales, interpretaciones preliminares.

Fase de exposición: intérprete dinámico, en ella se exponen explícitamente el mensaje (producto, película, información), el intérprete es dinámico porque en ese momento está realizando una decodificación del discurso mediático, es cuando se produce realmente el efecto directo del signo sobre el intérprete. 
Fase de post-exposición: intérprete final, se refiere al efecto que ha producido el signo en el intérprete y que le permitirá desarrollar sus efectos de forma completa. No se puede establecer un final para esta etapa pues los signos siempre se reciclan y modifican.

Estas 3 fases estarían dentro de lo que Jensen citado por Romero (2002) denomina "tiempo dentro de la cultura", que sería el aspecto continuo y constitutivo de las prácticas sociales, una semiosis social situada dentro de un tiempo y una cultura, cuando los significados han empezado a circular. Por otra parte estaría el "tiempo fuera de la cultura" que sería la práctica social separada y externa al proceso de semiosis, es decir, cuando los signos y significados aún no se han expuesto o introducido a la sociedad.

\section{Metodología}

La presente investigación está delimitada dentro del área de la lingüística, específicamente en referencia a la semiótica. La naturaleza de la investigación es de tipo descriptiva, porque se propone caracterizar la presencia de la semiótica en la sociedad. El diseño fue no-experimental por cuanto no se manipuló deliberadamente la variable semiótica en la sociedad. Igualmente, la investigación siguió una tipología documental, en la que según Balestrini (2006), la recolección de la información se encuentra vinculada a la delimitación de un diseño bibliográfico a partir de la consulta de libros y documentos de internet, los cuales sirvieron de apoyo y respaldo al estudio planteado. De acuerdo con su intención, la misma asumió una postura epistemológica basada en el idealismo-deductivo, en tanto que se partió del conocimiento previo de la semiótica en la sociedad para presentar resultados hermenéuticos de carácter objetivo acerca de sus teorías.

\section{Análisis de los resultados}

Del análisis de los contenidos teóricos consultados, se pudo constatar lo siguiente:

Se pudo constar que la semiótica también estudia los signos a nivel general y a los lingüísticos que están relacionados totalmente a la semántica y sobre todo a la escritura como semióticos. Los signos pueden ser interpretados diferentes tanto por los humanos como en la naturaleza.

Se pudo constatar que autores como Saussure y Buyssens, entre otros, coinciden en que la semiótica no se trata de un acto de lectura sino más bien se trata de una actitud de búsqueda de lo 
que existe de toda significación como por ejemplo sus raíces y los mecanismos mismos que la llegan a sostener.

Fue posible develar que el ser humano, para poder adaptarse a los diferentes sistemas que utiliza la comunicación, debe utilizar ciertos métodos; y es aquí donde entra la semiótica como una disciplina que se encarga del análisis de los signos o el estudio del funcionamiento del sistema de signos.

Puede considerarse no responsable a la semiótica de las variaciones incorrectas en la forma del lenguaje escrito y del oral; aunque si se encargue de estudiar toda la gama de estas variaciones dentro del contexto actual.

\section{Conclusiones}

La semiótica es la concordancia que existe entre un objeto y su interpretación, lo que vemos y lo que nos dice es decir nos transmite un mensaje, el mismo que es comprendido por todos los seres humanos que hablamos una misma lengua.

Las formas y perfiles a las que les hemos dado un conocido significado para entendernos entre todos por medio de las relaciones que se implantan entre las numerosas características de cada signo. Algunos de los cuales son obtenidos en base a la experiencia, otros son sencillamente un hecho, y otros se obtienen por prueba y error. La sociedad aprende de sus errores y adquiere experiencia, la misma que la lleva a superarse día a día.

\section{Referencias Bibliográficas}

Balestrini, M. (2006). Cómo se elabora el proyecto de investigación. Caracas, Consultores Asociados

Buyssens, E. (2012). Semiótica-Introducción. Recuperado en:

https://www.slideshare.net/MICKIIMICHAEL/semioticaintroduccin

Chandler, D. (2007). Semiotics for Beginners, Ed. Routledge, Londres, url: http://www.aber.ac.uk/media/Documents/S4B/semiotic.html. 
Ferdinad de Saussure. (2007). Curso de lingüística general, Distribuciones Fontamara, México, 2008.

Pérez, J. y Gardey, A. (2008). The Economy Journal. Recuperado en https://www.theeconomyjournal.com/firmas/julianperezporto

Romero, J. (2002). Disney i la transmissió de valors sòcio-culturals als nens: Anàlisi semiòticofreqüencial de la recepció. Aproximació a la investigació de l'audiència des de la Semiòtica Social. Barcelona: UAB.

Umberto, Eco. (2005). Tratado de semiótica general. Traducción de Carlos Manzano. Biblioteca umberto Eco. España. Editorial Lumen 